\title{
Patterns of recovery of intertidal organisms after compounded anthropogenic disturbances
}

\author{
J. P. Oliveira ${ }^{1,2, *}$, I. Sousa-Pinto ${ }^{2,3}$, G. M. Weber ${ }^{1,2,4}{ }^{\text {, I. Bertocci }}{ }^{2}$ \\ ${ }^{1}$ Estação Litoral da Aguda, Rua Alfredo Dias, praia da Aguda, 4410-475 Arcozelo/VNG, Portugal \\ ${ }^{2}$ CIMAR/CIIMAR - Centro Interdisciplinar de Investigação Marinha e Ambiental, Universidade do Porto, \\ Rua dos Bragas 289, 4050-123 Porto, Portugal \\ ${ }^{3}$ Department of Biology, Faculty of Sciences, University of Porto, Rua do Campo Alegre s/n, 4169-007, Porto, Portugal \\ ${ }^{4}$ ICBAS - Institute of Biomedical Sciences Abel Salazar, Rua de Jorge Viterbo Ferreira n. ${ }^{\circ} 228,4050-313$ Porto, Portugal
}

\begin{abstract}
Coastal habitats are exposed to increasing human and natural disturbances, including extraction of organisms and extreme climatic events. Patterns of recovery (i.e. convergence towards an unmanipulated control) of the structure of benthic assemblages, the total number, and the abundance of individual taxa were examined over a period of $15 \mathrm{mo}$ after the end of a previous experiment. In that experiment, crossed manipulations of levels of mussel harvesting and of the temporal patterns of storm-related mechanical disturbance (in terms of changes in variance but not in the overall intensity) were performed on north Portugal rocky shores. Effects of past disturbances were mostly detected at 3 and 9 mo after the end of disturbances, while no significant differences between unmanipulated and treated assemblages were present after $15 \mathrm{mo}$. These findings confirm that intertidal assemblages subjected to even extreme combinations of past disturbances can recover in a relatively short time. Important effects present after 3 to 9 mo were associated with the timing of disturbance, likely depending on interactions with life-history traits such as peaks in reproduction and recruitment. Contrary to theories considering disturbances as opportunities for some organisms to replace competitors that dominate space in undisturbed conditions, we observed changes in the abundances of the same taxa rather than their replacement. The present evidence contributes to the understanding of how multiple anthropogenic pressures affect the ability of intertidal assemblages to recover after disturbance.
\end{abstract}

KEY WORDS: Climate change - Human impact - Multiple disturbances · Foundation species · Intertidal $\cdot$ Recovery patterns $\cdot$ Abundance $\cdot$ Temporal variance

\section{INTRODUCTION}

Marine systems are globally exposed to considerable and increasing anthropogenic and natural perturbations operating over a range of scales (Sala et al. 2000, Halpern et al. 2008). Coastal areas, besides being exposed to anthropogenic activities that increase inputs of contaminants and nutrients (Vitousek et al. 1997), extract natural habitats (Gray 1997, Airoldi \& Beck 2007) and promote biological invasions (e.g. Williams \& Smith 2007), have been used throughout human history as sources of food (Siegfried et al. 1994, Griffiths \& Branch 1997, Castilla 1999). Populations of different groups of animals are intensely collected all over the world for human consumption, animal feeding or baiting (Keough et al. 1993, Underwood 1993, Addessi 1994, Crowe et al. 2000). These activities, which normally exert their direct effects on a local scale, occur simultaneously and potentially interact with events occurring on larger scales, such as those related to climate change. In fact, empirical observations and models have 
shown and predicted drastic alterations of the regime of meteorological variables (including intensity, timing, frequency and variance) for the near future (Easterling et al. 2000, Muller \& Stone 2001, Meehl et al. 2007, Wong et al. 2014).

Both natural and anthropogenic disturbances, in general, are key forces structuring natural assemblages, as they can modify patterns of species distribution, abundance and diversity through complex interactions with life traits of organisms (Sousa 1984, Connell et al. 1997). On rocky shores, in particular, disturbances represent important mechanisms for releasing resources (i.e. freeing space first, but also light and nutrients) and maintaining heterogeneous assemblages by eliminating the most sensitive and competitively dominant species (Dayton 1971, Connell 1978, Lubchenco \& Menge 1978, Paine \& Levin 1981, Sousa 1984). Separate and interactive effects of the intensity and timing of disturbance and of the life traits of organisms can drastically affect not just the structure of intertidal assemblages (Keough 1984, Breitburg 1985, Reed 1990, Airoldi 2000, BenedettiCecchi 2000, Bertocci et al. 2005), but also their functional characteristics, including their ability to recover once the disturbance is over (Underwood et al. 1983, Blanchette 1996, Bevilacqua et al. 2006, Oliveira et al. 2011). This last property is strictly related, although not necessarily scaled linearly (e.g. Cervin et al. 2005), with the intensity and timing of disturbance (Speidel et al. 2001, Carr et al. 2003) and interacts with other abiotic and biological processes that are variable in space and time. For instance, the availability of propagules (e.g. Hoffmann \& Ugarte 1985) and the presence of physical stress (e.g. Bell 1993) can drastically affect the way different species use resources made available by disturbance (Connell \& Keough 1985, Watling \& Norse 1998) and, therefore, how they replace each other during the subsequent recovery (O'Connor \& Anderson 2010, Maggi et al. 2011). Most previous studies have examined the effects of changes in multiple attributes of single disturbances, such as scouring (e.g. van Tamelen 1996, Vaselli et al. 2008), temperature extremes (e.g. Menge \& Sutherland 1987) and storms (e.g. Alvarado et al. 2001), on patterns of convergence of disturbed assemblages towards those from reference areas (Underwood 1989). There is a general lack of empirical studies specifically designed to examine the effects of attributes of compounded perturbations (e.g. Paine et al. 1998) on the recovery process (but see Tamburello et al. 2014), particularly in terms of temporal trajectories (the shapes of the curves describing fluctuations in the abundance of individ- ual taxa or in the structure of whole assemblages over the examined period (e.g. Bevilacqua et al. 2006) of recovery. Such manipulative experiments are needed since the wide range of multiple disturbances natural assemblages are currently exposed to, and their often unpredictable nature, make it almost impossible to extrapolate general patterns of recovery of populations and assemblages. Realistic manipulations of multiple anthropogenic stressors are essential in understanding and, possibly predicting, the causes of temporal variations in assemblages, which can affect ecologically relevant properties such as productivity (Johnson et al. 1996, Grime et al. 2000), stability and extinction risk (Micheli et al. 1999, Lundberg et al. 2000, Inchausti \& Halley 2003).

A previous manipulative experiment performed at multiple rocky shores in north Portugal was aimed at examining the effects of local harvesting of the habitat-forming mussel Mytilus galloprovincialis Lamarck, and of storm-related mechanical disturbance varying in temporal variance, on benthic assemblages associated with mussel beds (Oliveira et al. 2014). That experiment involved crossed manipulations of 4 levels of mussel harvesting with 2 levels of temporal patterning (evenly vs. irregularly distributed events, once the total intensity of disturbance was maintained over the period of the experiment) of storm-like mechanical disturbance. These crossed manipulations aimed to assess how an intact or increasingly damaged mussel bed could protect associated organisms from the impact of extreme storms, whose temporal patterns of occurrence would vary due to climate change. In the present study, the same experimental sites and units of the previous manipulative experiment were tracked over 15 mo after the end of all manipulations, in order to follow patterns of recovery (i.e. the degree of convergence towards the unmanipulated control) of assemblages and individual taxa, and to assess how these patterns were affected by the different combinations of past disturbances. Specifically, the main finding from previous manipulations was that mussels could effectively buffer the effects of mechanical disturbance, particularly when the mussel bed was left intact and disturbance was relatively less stressful (e.g. under the regular treatment, compared to that involving multiple events aggregated over short periods). From this finding, it could be hypothesized that assemblages from patches that were previously allocated to the experimental combination of an intact mussel bed and regularly distributed events of mechanical disturbance, would be characterized by the greatest similarity and fastest convergence towards unmanip- 
ulated assemblages. At the other extreme, manipulated patches, where mussels were completely removed in combination with irregular disturbance events, would host the most different assemblages compared to the unmanipulated patches and would take the longest time to convergence to the unmanipulated patches. Intermediate outcomes would be expected for the other combinations of past experimental disturbances. Such hypotheses were tested in the present study; response variables included both average responses measured at the beginning (3 mo of recovery), in the middle ( $9 \mathrm{mo}$ ) and at the end (15 mo) of the examined period, and temporal trajectories (quantified as variances calculated over 5 sampling periods) of the structure of whole assemblages, the total richness of taxa and the abundance of individual taxa.

\section{MATERIALS AND METHODS}

\section{Collection of data}

Data were collected between October 2012 and October 2013 at the same study sites (Aguda and Marreco: $41^{\circ} 2.71^{\prime} \mathrm{N}, 8^{\circ} 39.20^{\prime} \mathrm{W}$ and $41^{\circ} 14.12^{\prime} \mathrm{N}$, $8^{\circ} 43.45^{\prime} \mathrm{W}$, respectively) and on the same units of a previous manipulative experiment which ended in July 2012. The study system and past experimental procedures are illustrated in detail in Oliveira et al. (2014). In summary, the intensity of mussel harvesting and the temporal variance of storm-related mechanical disturbances were manipulated according to a partially asymmetrical design. This design crossed 4 levels of harvesting ('0', '30', '60' and '100', corresponding to no harvest, mussels reduced to
$70 \%$ cover, mussels reduced to $40 \%$ cover, and mussels completely removed, respectively) with 1 regular and 2 irregular temporal patterns of mechanical disturbance produced with a hand rake. The regular treatment involved a total of 6 events evenly distributed over a period of $18 \mathrm{mo}$, while the irregular patterns involved the same 6 events clustered in shorter periods, separated by prolonged periods without disturbance. Two different sequences of events were replicated in the irregular treatment, but not in the regular one (Fig. 1). Three independent plots $(35 \times 35$ $\mathrm{cm})$ were allocated to each combination of these factors and 3 additional plots were left unmanipulated as control.

In the present study, the same 39 plots at each site were sampled during 5 periods (October 2012, January, April, June and October 2013) corresponding to $3,6,9,12$ and 15 mo after the end of experimental manipulations. At each sampling period, the percentage cover of sessile taxa and the number of individuals of mobile animals were visually estimated using a $30 \times 30 \mathrm{~cm}$ frame placed in the centre of each plot following the same procedures described in Oliveira et al. (2014).

\section{Data analyses}

A total of 27 taxa (including 15 macroalgae and 12 animals) were identified throughout the study. Multivariate and univariate statistical techniques were used to compare patterns of recovery of the structure of whole assemblages, the richness of taxa and the abundance of the most common individual taxa between plots allocated to different combinations of past disturbances. Response variables were exam-

Regular (Reg)

\begin{tabular}{|c|c|c|c|c|c|c|c|c|c|c|c|c|c|c|c|c|c|c|c|c|}
\hline $\mathrm{X}$ & & & $\mathrm{X}$ & & & $\mathrm{X}$ & & & $\mathrm{x}$ & & $\mathrm{X}$ & & & $\mathrm{X}$ & & $----\mathrm{T} 1----$ & $-1-1$ & $-\mathrm{T} 2-\cdots$ & 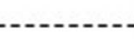 & T3 \\
\hline \multicolumn{16}{|c|}{ Irregular, Sequence 1 (Irr-S1) } & \multirow{2}{*}{\multicolumn{5}{|c|}{ ]- T1- }} \\
\hline \begin{tabular}{l|l}
$\mathrm{X}$ \\
\end{tabular} & & & & $\mathrm{X}$ & & & & & & & $\mathrm{X}$ & $\mathrm{X}$ & $\mathrm{X}$ & & & & & & & \\
\hline \multicolumn{16}{|c|}{ Irregular, Sequence 2 (Irr-S2) } & \multirow{2}{*}{\multicolumn{5}{|c|}{ 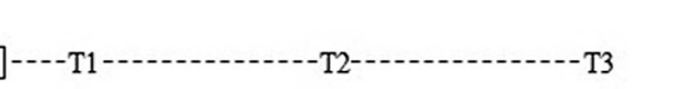 }} \\
\hline $\mathrm{X}$ & & & & $\mathrm{X}$ & $\mathrm{X}$ & $\mathrm{X}$ & & & & & & & $\mathrm{X}$ & $\mathrm{X}$ & & & & & & \\
\hline \multirow{2}{*}{$\begin{array}{l}F \quad M \\
2011\end{array}$} & & \multirow{2}{*}{ M } & \multirow{2}{*}{$\mathrm{J}$} & \multirow{2}{*}{$\mathrm{J}$} & \multirow[t]{2}{*}{ A } & \multirow[t]{2}{*}{ S } & \multirow[t]{2}{*}{0} & \multirow{2}{*}{$\mathrm{N}$} & \multirow{2}{*}{ D $\underset{2012}{\mathrm{~J}}$} & \multirow{2}{*}{ F } & \multirow{2}{*}{$\mathrm{M}$} & \multirow{2}{*}{ A } & \multirow[t]{2}{*}{$\mathrm{M}$} & \multirow{2}{*}{\multicolumn{2}{|c|}{$\mathrm{J}$}} & Oct & Jan & Apr & Jun & Oct \\
\hline & & & & & & & & & & & & & & & & $\begin{array}{l}2012 \\
(3 \mathrm{mo})\end{array}$ & $\begin{array}{l}2013 \\
(6 \mathrm{mo})\end{array}$ & $\begin{array}{l}2013 \\
(9 \mathrm{mo})\end{array}$ & $\begin{array}{l}2013 \\
(12 \mathrm{mo})\end{array}$ & $\begin{array}{l}2013 \\
(15 \mathrm{mo})\end{array}$ \\
\hline
\end{tabular}

Fig. 1. Design of the temporal arrangements of events $(\mathrm{X})$ of mechanical disturbance (crossed with 4 levels of intensity of mussel harvesting in the full experiment, as described in detail in Oliveira et al. 2014) of the previous manipulative experiment and sampling design of the present recovery study. The recovery study included 5 sampling times, out of which 3 (T1, T2 and T3) were statistically analysed 
ined both in terms of average responses at the beginning (October 2012), in the middle (April 2013) and at the end (October 2013) of the examined period, and of temporal variances calculated over the 5 sampling periods (see Fig. 2). All analyses were based on the same model that included a first partitioning of the total variability into the Control vs. Treatments contrast and the Among treatments variation. The second term was then partitioned into the main effects of harvesting intensity (I), mechanical disturbance variability $(\mathrm{V})$, and their interaction, with each term involving temporal variability further partitioned into a Regular vs. Irregular contrast and Between sequences (S) variation (see Oliveira et al. 2014 for details and Table 1 for an illustration of all tested sources of variability).

Permutational multivariate analysis of variance (PERMANOVA, Anderson 2001) based on BrayCurtis untransformed dissimilarities was used to examine differences in the structure of whole assemblages at each of the 3 recovery periods reported above. When the low number of permutations prevented enough powerful tests, a p-value was calculated using 999 Monte Carlo draws from the appropriate asymptotic permutation distribution (Anderson \& Robinson 2003). When relevant, Student's $t$ tests were used for post-hoc comparisons.

Differences in temporal trajectories of whole assemblages were tested by calculating measures of multivariate variance over the 5 sampling periods following an approach for partitioning variation among factors that was successfully extended from univariate to multivariate data (Terlizzi et al. 2007). Estimates of temporal variance of the structure of assemblages were obtained by performing a 1-way PERMANOVA separately for each plot, with time as a factor. Multivariate pseudo-variance components were then calculated analogously to univariate ANOVA estimators, i.e. by equating observed mean squares and mean squares expected from the linear model of the analysis (Searle et al. 1992, Underwood, 1997, Terlizzi et al. 2007). Negative estimates of pseudo-variance were set to zero, being interpreted as sample underestimates of very small or null variances (Searle et al. 1992, Underwood 1996). This procedure generated 3 replicate measures (one for each plot) of pseudo-variance components for each combination of past experimental treatments, including the unmanipulated control, that were finally analyzed with ANOVA according to the model illustrated in Table 1.

Analogous procedures based on ANOVA were used to test for differences in mean values and temporal variances of the richness of taxa and of the abundance of individual taxa. Before each ANOVA, the assumption of homogeneity of variances was checked with Cochran's $C$ test and data were $\log (x+1)$ transformed when necessary. When the transformation could not make variances homogeneous, untransformed data were analyzed and results considered robust if not significant (at $p>0.05$ ) or, considered significant at $p<0.01$ to compensate for the increased probability of Type I error (Underwood 1997). When relevant, Student-Newman-Keuls (SNK) tests were used for posthoc comparisons of means.

Differences in the structure of whole assemblages were visualized by calculating centroids of assemblages according to results of the analyses for October 2012, April 2013 and October 2013 and those for multivariate temporal variance. For this goal, principal coordinates were calculated from the Bray-Curtis dissimilarity matrix of original data. Centroids were obtained by averaging principal coordinates according to each relevant experimental condition and sampling period (McArdle \& Anderson 2001). Finally, non-metric multidimensional scaling (nMDS) ordination plots based on Euclidean distances were displayed.

Multivariate analyses were carried out using the PRIMER 6.0 and PERMANOVA package (Anderson et al. 2008). Univariate analyses were carried out using GMAV-5 for Windows (Underwood et al. 2002).

\section{RESULTS}

\section{Whole assemblage}

Three months after the end of the disturbance experiment, assemblages differed between the unmanipulated plots and, on average, those allocated to manipulations in both Aguda (Table 1A, Fig. 2) and Marreco (Table 1B, Fig. 2). In addition, the significant $\mathrm{I} \times \mathrm{S}$ interaction observed only in Aguda indicated an existing effect of the intensity of harvesting that was not consistent between the 2 sequences of irregular disturbance (Table 1A, Fig. 2). Assemblages from unmanipulated plots, in particular, differed from those in plots subjected to the lowest level of mussel removal (treatment ' 30 ') combined with sequence 1 (Student's $t=2.241, \mathrm{p}<0.05$ ) of irregular disturbance events, and those in plots completely deprived of mussels (treatment '100') combined with sequence 2 (Student's $t=3.590, \mathrm{p}<0.01$ ) (Fig. 2). Nine months after the end of the experiment, control and manipulated plots still differed only in Marreco, while the 
Table 1. PERMANOVA on the structure of assemblages sampled at 3,9 and 15 mo after the end of the disturbance experiment in (A) Aguda and (B) Marreco. Significant effects in bold

\begin{tabular}{|c|c|c|c|c|c|c|c|c|c|c|c|}
\hline \multirow[t]{2}{*}{ Source of variation } & \multirow[t]{2}{*}{ df } & \multicolumn{3}{|c|}{3 mo (Oct 2012) } & \multicolumn{3}{|c|}{9 mo (Apr 2013) } & \multicolumn{3}{|c|}{15 mo (Oct 2013) } & \multirow{2}{*}{$\begin{array}{l}\text { Permutable units } \\
\text { and denominator }\end{array}$} \\
\hline & & MS & pseudo- $F$ & $F \quad \mathrm{p}$ & MS & pseudo- $I$ & $F \mathrm{p}$ & MS & pseudo & $-F \mathrm{p}$ & \\
\hline \multicolumn{12}{|l|}{ (A) Aguda } \\
\hline Among experimental levels & 12 & 0.12 & 2.24 & 0.007 & 0.09 & 1.75 & 0.068 & 0.05 & 0.75 & 0.810 & 39 replicate plots \\
\hline Control vs. treatments & 1 & 0.14 & 2.67 & 0.048 & 0.12 & 2.34 & 0.091 & 0.05 & 0.70 & 0.526 & 39 replicate plots \\
\hline Among treatments & 11 & 0.12 & 2.20 & 0.007 & 0.09 & 1.69 & 0.082 & 0.05 & 0.75 & 0.794 & 39 replicate plots \\
\hline Temporal variability $=\mathrm{V}$ & 2 & 0.12 & 2.27 & 0.047 & 0.11 & 2.17 & 0.087 & 0.01 & 0.16 & 0.981 & 39 replicate plots \\
\hline Regular vs. Irregular & 1 & 0.19 & 4.35 & $0.128^{\mathrm{MC}}$ & 0.21 & 13.02 & $\mathbf{0 . 0 4 4}{ }^{M C}$ & 0.01 & 1.46 & $0.423^{\mathrm{MC}}$ & 3 among seq. cells ${ }^{a}$ \\
\hline Between sequences $=\mathrm{S}$ & 1 & 0.04 & 0.85 & 0.464 & 0.02 & 0.31 & 0.751 & 0.01 & 0.02 & 0.975 & 39 replicate plots \\
\hline Harvesting intensity = I & 4 & 0.12 & 2.35 & 0.043 & 0.13 & 2.49 & 0.048 & 0.09 & 1.31 & 0.222 & 39 replicate plots \\
\hline $\mathrm{I} \times \mathrm{V}$ & 6 & 0.11 & 2.09 & 0.028 & 0.06 & 1.13 & 0.355 & 0.05 & 0.67 & 0.802 & 39 replicate plots \\
\hline $\mathrm{I} \times$ Regular vs. Irregular & 3 & 0.08 & 0.60 & $0.750^{\mathrm{MC}}$ & 0.06 & 0.98 & $0.398^{\mathrm{MC}}$ & 0.05 & 0.94 & $0.507^{\mathrm{MC}}$ & $9 \mathrm{I} \times \mathrm{S}$ cells ${ }^{\mathrm{b}}$ \\
\hline $\mathrm{I} \times \mathrm{S}$ & 3 & 0.14 & 2.62 & 0.021 & 0.06 & 1.14 & 0.379 & 0.05 & 0.69 & 0.722 & 39 replicate plots \\
\hline Residual & 26 & 0.05 & & & 0.05 & & & 0.07 & & & \\
\hline \multicolumn{12}{|l|}{ (B) Marreco } \\
\hline Among experimental levels & 12 & 0.13 & 1.51 & 0.033 & 0.12 & 1.18 & 0.216 & 0.10 & 1.27 & 0.291 & 39 replicate plots \\
\hline Control vs. treatments & 1 & 0.47 & 5.27 & 0.002 & 0.50 & 4.71 & 0.002 & 0.07 & 0.91 & 0.349 & 39 replicate plots \\
\hline Among treatments & 11 & 0.10 & 1.17 & 0.231 & 0.09 & 0.86 & 0.712 & 0.10 & 1.31 & 0.276 & 39 replicate plots \\
\hline Temporal variability = V & 2 & 0.07 & 0.80 & 0.629 & 0.04 & 0.39 & 0.955 & 0.11 & 1.50 & 0.154 & 39 replicate plots \\
\hline Regular vs. Irregular & 1 & 0.10 & 2.42 & $0.183^{\mathrm{MC}}$ & 0.08 & 14.76 & $\mathbf{0 . 0 1 1} \mathrm{MC}$ & 0.10 & 0.79 & $0.609 \mathrm{MC}$ & 3 among seq. cells ${ }^{\mathrm{a}}$ \\
\hline Between sequences $=\mathrm{S}$ & 1 & 0.04 & 0.47 & 0.816 & 0.01 & 0.05 & 0.992 & 0.13 & 1.68 & 0.162 & 39 replicate plots \\
\hline Harvesting intensity = I & 4 & 0.15 & 1.70 & 0.061 & 0.13 & 1.19 & 0.270 & 0.11 & 1.52 & 0.114 & 39 replicate plots \\
\hline $\mathrm{I} \times \mathrm{V}$ & 6 & 0.09 & 1.03 & 0.431 & 0.09 & 0.85 & 0.661 & 0.09 & 1.14 & 0.370 & 39 replicate plots \\
\hline I $\times$ Regular vs. Irregular & 3 & 0.07 & 0.67 & $0.762^{\mathrm{MC}}$ & 0.09 & 0.98 & $0.503^{\mathrm{MC}}$ & 0.04 & 0.29 & $0.778^{\mathrm{MC}}$ & $9 \mathrm{I} \times \mathrm{S}$ cells ${ }^{\mathrm{b}}$ \\
\hline $\mathrm{I} \times \mathrm{S}$ & 3 & 0.11 & 1.23 & 0.245 & 0.09 & 0.86 & 0.608 & 0.13 & 1.77 & 0.052 & 39 replicate plots \\
\hline Residual & 26 & 0.09 & & & 0.11 & & & 0.08 & & & \\
\hline \multicolumn{12}{|c|}{$\begin{array}{l}\text { aOne regular and } 2 \text { irregular sequences were used as permutable units, but only irregular sequences were used for calculating } \\
\text { denominator MS } \\
\text { bOne regular and } 8 \text { intensity } \times \text { sequence cells were used as permutable units, but only intensity } \times \text { sequence cells were used for } \\
\text { calculating denominator MS } \\
{ }^{\mathrm{MC}} \text { p-values calculated using the Monte Carlo method }\end{array}$} \\
\hline
\end{tabular}

temporal variability of past disturbance was associated with different assemblages at both study sites, independent of harvesting intensity (Table 1). A main effect of harvesting intensity was instead detected in Aguda; this was driven by the difference between unmanipulated assemblages and those from plots where the mussel bed had been fully removed (Table 1A, Fig. 2; Student's $t=2.948, \mathrm{p}<0.05$ ). No main or interactive effects of past experimental disturbances were detected at 15 mo of recovery time at both sites (Table 1, Fig. 2).

In both Aguda and Marreco, no significant effects of past disturbances were documented on the multivariate temporal variance of the structure of assemblages over the course of the recovery study; however, the relatively high $F$-value obtained for the contrast Regular vs. Irregular could suggest a relevant effect of the temporal patterning of past disturbance, which was probably not detected as significant due to the low power of the test that involved only one degree of freedom at both the numerator and the denominator (Table 2). Nevertheless, MDS plots showed a large degree of overlap between the temporal trajectories of assemblages that were previously subjected to regular and irregular events of disturbance; these temporal trajectories generally tended to also run parallel to that of control assemblages (Fig. 3).

\section{Individual response variables}

Three months after the end of the manipulative experiment, the total number of taxa in Aguda differed between plots previously subjected to regular events of disturbance and those where disturbance was applied irregularly over time (Table 3A). The irregular treatment, in particular, was associated with a higher richness of taxa compared to the regular treatment. However, the absolute difference (although proportionally important) was just by a single taxon (i.e. on average, $\sim 5$ taxa in the Regular and 

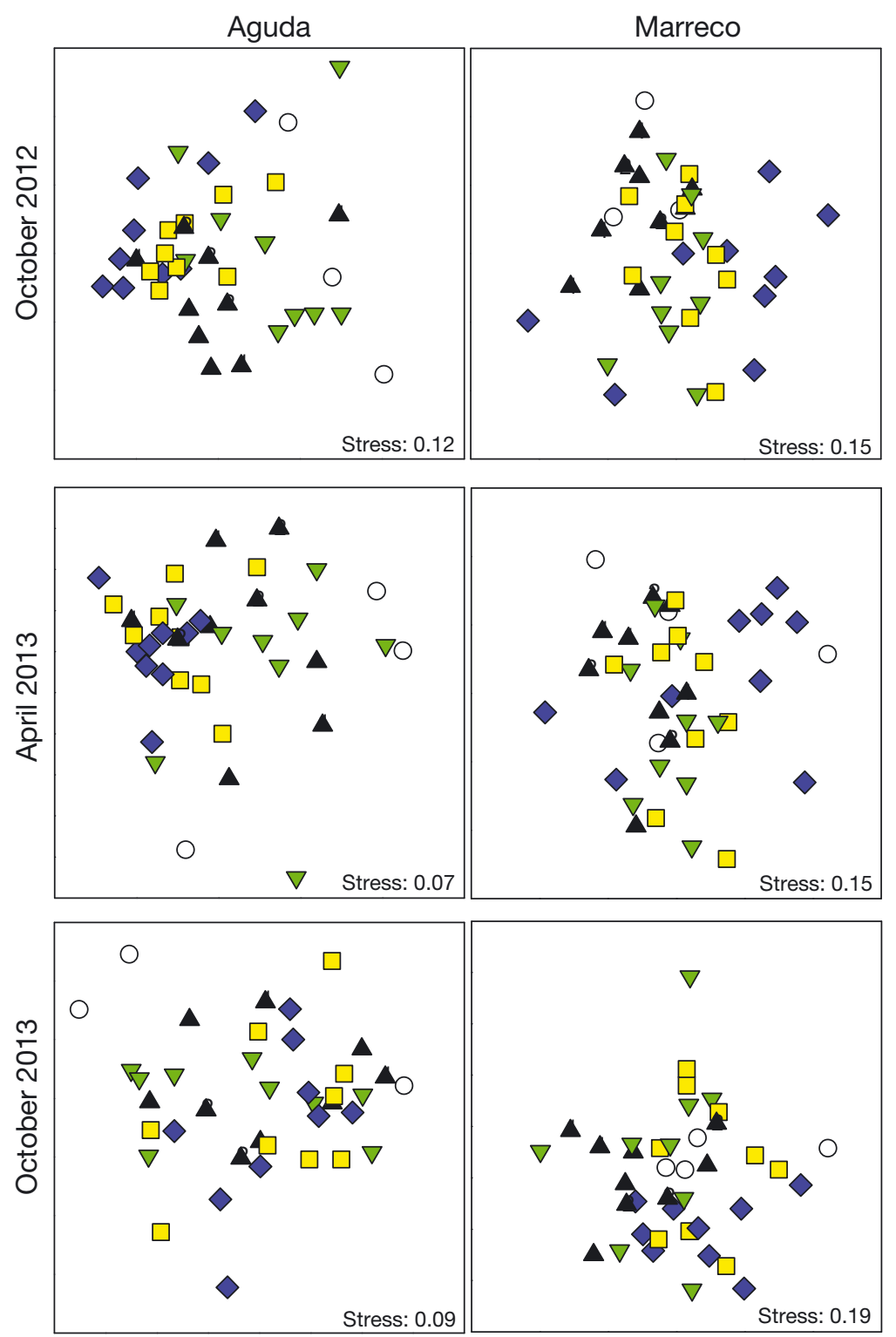

Fig. 2. nMDS plots comparing assemblages from the 2 study sites (Aguda and Marreco) at 3, 9 and 15 mo (October 2012, April 2013 and October 2013, respectively) after the end of experimental manipulations. Each symbol represents the centroid of assemblages calculated over replicate unmanipulated plots $(\mathrm{O})$ and plots assigned to each past combination of intensity of mussel harvesting (black: '0' \% removal; green: '30' \% removal; yellow: '60' \% removal; blue: '100' \% removal; Oliveira et al. 2014) at different temporal variabilities of mechanical disturbance $(\square$ : Regular treatment;

$\Delta$ : Irregular treatment, sequence $1 ; \nabla$ : Irregular treatment, sequence 2)

6 taxa in the Irregular treatment; Fig. 4A). At the same site, effects of the intensity of mussel harvesting were found in April 2013 (9 mo of recovery), although effects were variable depending on the irregular sequence of mechanical disturbance. The ' 30 ' level of mussel removal combined with sequence 1 resulted in a higher number of taxa than any other intensity, while no significant differences were caused by the intensity of harvesting when combined with sequence 2 of events of disturbance (Table 3A, Fig. 4A; SNK test). Differences in the average total number of taxa were not yet evident in Aguda in October 2013 (Table 3A, Fig. 4A), and were never detected in Marreco (Table 3B, Fig. 5A). However, variations in the total number of taxa over the whole examined period of recovery drove significant differences in the temporal variance of this variable, with patterns being inconsistent between sites. In Aguda, temporal fluctuations in the richness of taxa were larger in unmanipulated than in treated plots on average (Table 4, Fig. 4A). In Marreco, regularly distributed past events of disturbance were associated with a larger temporal variance of the total number of taxa of recovering assemblages compared to irregular events (Table 4, Fig. 5A).

Significant differences in the mean abundance of the target species (Mytilus galloprovincialis) of the past experimental harvesting were detected at each of the 3 analyzed sampling periods. In October 2012, the cover of mussels was higher in control than in treated plots and was affected by the intensity of harvesting in both Aguda (Table 3A) and Marreco (Table 3B). In Aguda, mussels were more abundant in plots that were initially subjected to the lower level of harvesting (' 30 ' treatment) than in plots allocated to the complete removal, with the unmanipulated control and the ' 60 ' treatment being inconsistently ranked between the ' 30 ' and ' 100 ' levels (Fig. 4B; SNK test). In Marreco, the cover of mussels in control plots was almost double that in plots assigned to both intermediate levels of harvesting, and was further reduced to approx. one-fourth in complete removal plots (Fig. 5B; SNK test). In April 2013, the cover of $M$. galloprovincialis was affected by the intensity of harvesting, with patterns being similar in both Aguda and Marreco; values progressively decreased from unmanipulated plots to those allocated to both intermediate harvesting levels to those where mussels had been completely removed (Table 3, 
Table 2. ANOVA on multivariate temporal variance of the structure of assemblages over the recovery period at each study site

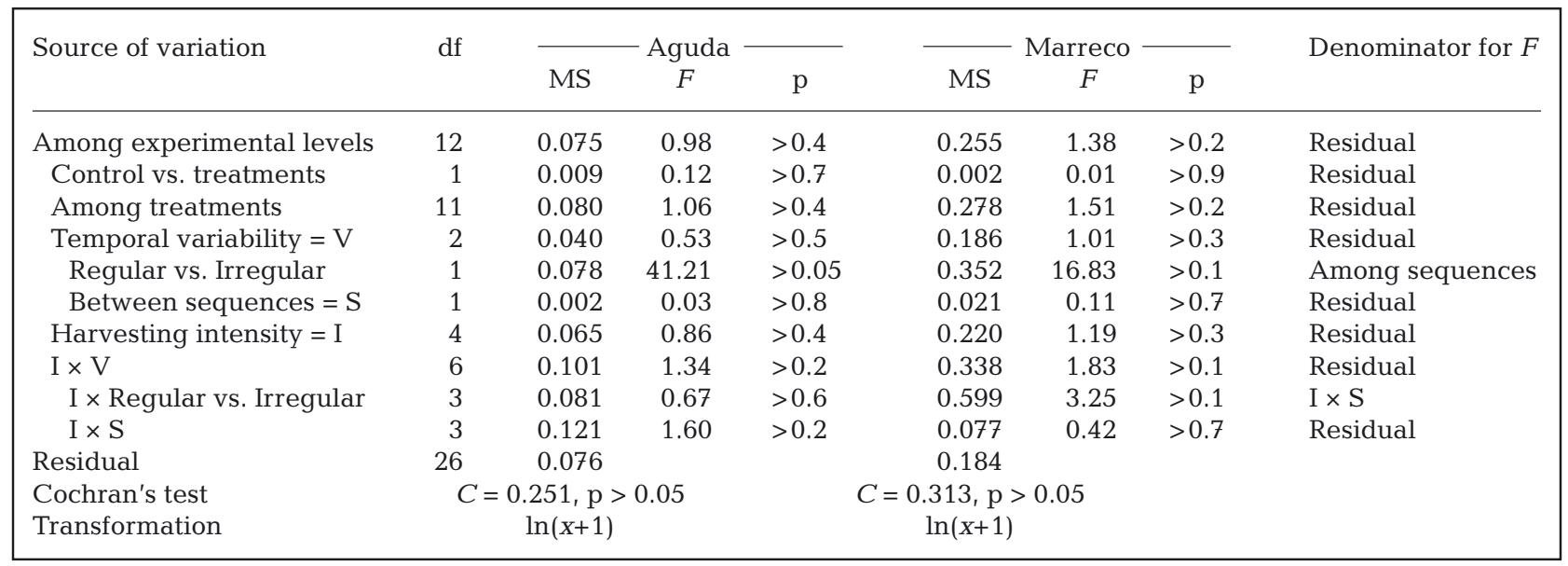
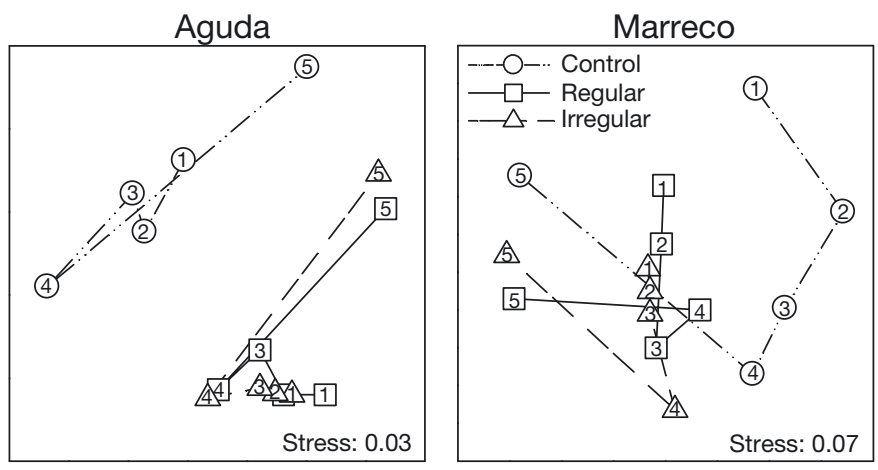

Fig. 3. nMDS plots of the temporal trajectories of assemblages from unmanipulated (control) plots (centroids calculated over replicate plots) and plots assigned to past Regular (centroids calculated over replicate plots and 4 levels of mussel harvesting) and Irregular (centroids calculated over replicate plots, 2 temporal sequences and 4 levels of mussel harvesting) treatments of mechanical disturbance, sampled 5 times (from 1 to 5: October 2012, January, April, June and October 2013, respectively corresponding to $3,6,9,12$ and 15 mo of recovery)

Figs. 4B \& 5B; SNK test). Together with a higher cover of mussels under the irregular treatment applied according to sequence 1 compared to sequence 2, exactly the same pattern as in April 2013 was still present in October 2013 in Marreco only (Table 3B, Fig. 5B; SNK test), while a difference between control and treated plots was again evident in Aguda, in the same direction as that displayed 1 yr earlier (Table 3A, Fig. 4B). Overall, temporal fluctuations in the abundance of the recovering mussels were larger in control than in treated plots at both study sites (Table 4, Figs. 4B \& 5B).

Articulated coralline algae of the genus Corallina responded to past treatments in a very similar way as the total number of taxa. In Aguda, this taxon was present in October 2012 in plots allocated to regu- larly distributed events of disturbance and absent in those allocated to the irregular pattern of disturbance (Table 3A, Fig. 4C). The Harvesting intensity $\times$ Sequence interaction was significant in April 2013, with Corallina spp. being present only in ' 30 ' treatment plots subjected to sequence 1 , and with the same abundance in control and ' 60 ' treatment plots subjected to sequence 2 of disturbance events (Table 3A, Fig. 4C). No significant differences were documented for the mean abundance of this algal group in Aguda at $15 \mathrm{mo}$ and in Marreco at 3, 9 and $15 \mathrm{mo}$ after the end of the manipulative experiment (Table 3, Figs. 4C \& 5C). Analogously, no effects of any past manipulations were shown in terms of temporal variance of the abundance of Corallina spp. (Table 4, Figs. 4C \& 5C).

Although absolute values were very low, the cover of encrusting coralline algae in Aguda was, on average, $15 \times$ higher in unmanipulated than in treated plots sampled 3 mo after the end of experimental disturbances, but this difference disappeared 6 and 12 mo later (Table 3A, Fig. 4D). In Marreco, this taxon contrastingly did not show significant responses to any past disturbance in October 2012, while interactive effects of the intensity of harvesting and the temporal variability of disturbance became evident later during the recovery period (Table 3B). In April 2012, encrusting corallines were absent in plots where the mussel bed had been left intact or slightly reduced (control and ' 30 ' treatment, respectively) if regularly distributed events of disturbance had been applied, while they increased in abundance (with mean cover values $~ 50 \%$ higher in the ' 30 ' treatment compared to the control) where disturbance had been irregularly applied. The opposite pattern was displayed in plots subjected to higher intensities of 
Table 3. Summary of significant results from the ANOVA on the total number of taxa and the abundance of individual taxa in (A) Aguda and (B) Marreco. $\mathrm{T} 1=3$ mo (October 2012), T2 = 9 mo (April 2013), T3 = 15 mo (October 2013). ${ }^{*} \mathrm{p}<0.05,{ }^{* *} \mathrm{p}<0.01,{ }^{* * *} \mathrm{p}<0.001$. Abbreviations as in Table 1

\begin{tabular}{|c|c|c|c|c|c|}
\hline Variable & Time & Source of variation & MS & $F$ & Transf. \\
\hline \multicolumn{6}{|l|}{ (A) Aguda } \\
\hline \multirow{2}{*}{$\begin{array}{l}\text { Total number } \\
\text { of taxa }\end{array}$} & $\mathrm{T} 1$ & Regular vs. Irregular & 0.06 & $555.0^{*}$ & None \\
\hline & $\mathrm{T} 2$ & $\mathrm{I} \times \mathrm{S}$ & 3.82 & $3.0^{*}$ & None \\
\hline \multirow{4}{*}{$\begin{array}{l}\text { Mytilus gallo- } \\
\text { provincialis }\end{array}$} & $\mathrm{T} 1$ & Control vs. treatments & 1720.43 & $6.1^{*}$ & None \\
\hline & & Harvesting intensity & 792.31 & $2.8^{*}$ & \\
\hline & $\mathrm{T} 2$ & Harvesting intensity & 0.77 & $3.5^{*}$ & $\ln (x+1)$ \\
\hline & T3 & Control vs. treatments & 205.34 & $4.5^{*}$ & None \\
\hline $\begin{array}{r}\text { Encrusting } \\
\text { corallines }\end{array}$ & $\mathrm{T} 1$ & Control vs. treatments & 4.77 & $13.8^{* *}$ & None $^{a}$ \\
\hline \multirow[t]{2}{*}{ Corallina spp. } & $\mathrm{T} 1$ & Regular vs. Irregular & 4.53 & $56.3^{*}$ & None $^{a}$ \\
\hline & $\mathrm{T} 2$ & $\mathrm{I} \times \mathrm{S}$ & 2.57 & $3.3^{*}$ & None \\
\hline \multirow{5}{*}{$\begin{array}{l}\text { Chthamalus } \\
\text { spp. }\end{array}$} & $\mathrm{T} 1$ & Control vs. treatments & 3573.21 & $16.8^{* * *}$ & None \\
\hline & & Between sequences & 2295.97 & $10.8^{* *}$ & \\
\hline & & Harvesting intensity & 2360.69 & $11.1^{* * *}$ & \\
\hline & $\mathrm{T} 2$ & Control vs. treatments & 3250.76 & $9.1^{* *}$ & None \\
\hline & & Harvesting intensity & 2654.17 & $7.4^{* * *}$ & \\
\hline \multirow[t]{3}{*}{ Patella spp. } & $\mathrm{T} 1$ & Control vs. treatments & 716.33 & $6.7^{*}$ & None \\
\hline & & $\mathrm{I} \times$ Regular vs. Irregular & 302.24 & $17.4^{*}$ & \\
\hline & $\mathrm{T} 2$ & Control vs. treatments & 302.09 & $6.1^{*}$ & None $^{a}$ \\
\hline \multirow[t]{4}{*}{ Bare rock } & $\mathrm{T} 1$ & Between sequences & 622.53 & $6.1^{*}$ & None \\
\hline & & Harvesting intensity & 510.77 & $5.0^{* *}$ & \\
\hline & $\mathrm{T} 2$ & Between sequences & 350.17 & $5.1^{*}$ & None \\
\hline & & Harvesting intensity & 222.59 & $3.2^{*}$ & \\
\hline \multicolumn{6}{|l|}{ (B) Marreco } \\
\hline \multirow{6}{*}{$\begin{array}{l}\text { Mytilus gallo- } \\
\text { provincialis }\end{array}$} & $\mathrm{T} 1$ & Control vs. treatments & 1624.24 & 8. $9^{* *}$ & None \\
\hline & & Harvesting intensity & 1514.07 & $8.3^{* *}$ & \\
\hline & $\mathrm{T} 2$ & Control vs. treatments & 1348.81 & $6.1^{*}$ & None \\
\hline & & Harvesting intensity & 762.87 & $3.4^{*}$ & None \\
\hline & T3 & Between sequences & 165.38 & $5.5^{*}$ & None \\
\hline & & Harvesting intensity & 107.56 & $3.6^{*}$ & \\
\hline \multirow{2}{*}{$\begin{array}{l}\text { Encrusting } \\
\text { corallines }\end{array}$} & $\mathrm{T} 2$ & $\mathrm{I} \times$ Regular vs. Irregular & 10.11 & $8.6^{*}$ & None \\
\hline & T3 & $\mathrm{I} \times \mathrm{V}$ & 0.16 & $2.7^{*}$ & $\ln (x+1)$ \\
\hline $\begin{array}{l}\text { Chthamalus } \\
\text { spp. }\end{array}$ & T3 & Between sequences & 181.50 & $7.4^{*}$ & None \\
\hline Gibbula spp. & $\mathrm{T} 1$ & $\mathrm{I} \times$ Regular vs. Irregular & 1.44 & $15.9^{*}$ & $\ln (x+1)$ \\
\hline \multirow[t]{2}{*}{ Patella spp. } & $\mathrm{T} 2$ & Regular vs. Irregular & 0.27 & $180.3^{*}$ & $\ln (x+1)$ \\
\hline & T3 & $\mathrm{I} \times \mathrm{V}$ & 156.31 & $4.1^{* *}$ & None \\
\hline Bare rock & $\mathrm{T} 2$ & $\mathrm{I} \times$ Regular vs. Irregular & 596.80 & $12.0^{*}$ & None \\
\hline
\end{tabular}

the mussel bed had been left intact when combined with sequence 1 of irregular disturbance, with comparable values in the '60' and '100' treatments when combined with regular disturbance (Table 3B, Fig. 5C; SNK test). However, these patterns were not accompanied by significant differences in the temporal variance of the abundance of these algae at both sites (Table 4).

The mean abundance of the other abundant algal group analyzed (the green foliose Ulva spp.) did not show any effect of past disturbances in both Aguda (Table 3A, Fig. 4E) and Marreco (Table 3B, Fig. 5E). Nevertheless, sequence 1 of past events of disturbance was associated with larger temporal fluctuations in the abundance of Ulva in Marreco over the recovery period compared to sequence 2 (Table 4, Fig. 5E).

The mean abundances of barnacles, Chthamalus spp., were higher in treated than in control plots sampled in Aguda at 3 and 9 mo, but not at 15 mo after the end of the previous experiment (Table 3A, Fig. 4F). Moreover, in October 2012, Aguda showed a higher cover of barnacles in plots that were previously disturbed using sequence 2 of past disturbance events compared to sequence 1 , and in plots where the mussel bed had been completely removed than in plots that were subjected to any other level of experimental harvesting, including the control (Table 3A, Fig. 4F). A similar main effect of harvesting intensity was also evident in April 2013, with barnacles being more abundant in

harvesting, with encrusting corallines being virtually absent where irregular events of disturbance had been performed, and present (with mean percentage covers reduced to approx. one-third in the '100' compared to the ' 60 ' treatment) where past disturbance had been established through regular events (Table 3B, Fig. 5C; SNK test). In October 2013, encrusting coralline algae were only present (with relatively doubled mean cover) in plots allocated to the complete removal of mussels and in those where both treatments where mussels had been more intensely removed ('60' and '100' treatments) than in the '30' level of harvesting and the control (Table 3A, Fig. 4F; SNK test). In Marreco, the only significant difference in the mean cover of Chthamalus spp. was observed in October 2013, when disturbance sequence 1 was associated with higher values than sequence 2 (Table 3B, Fig. 5F). Significant effects of past disturbances on the temporal variance of barnacles were detected only in Aguda (Table 4). Specifi- 

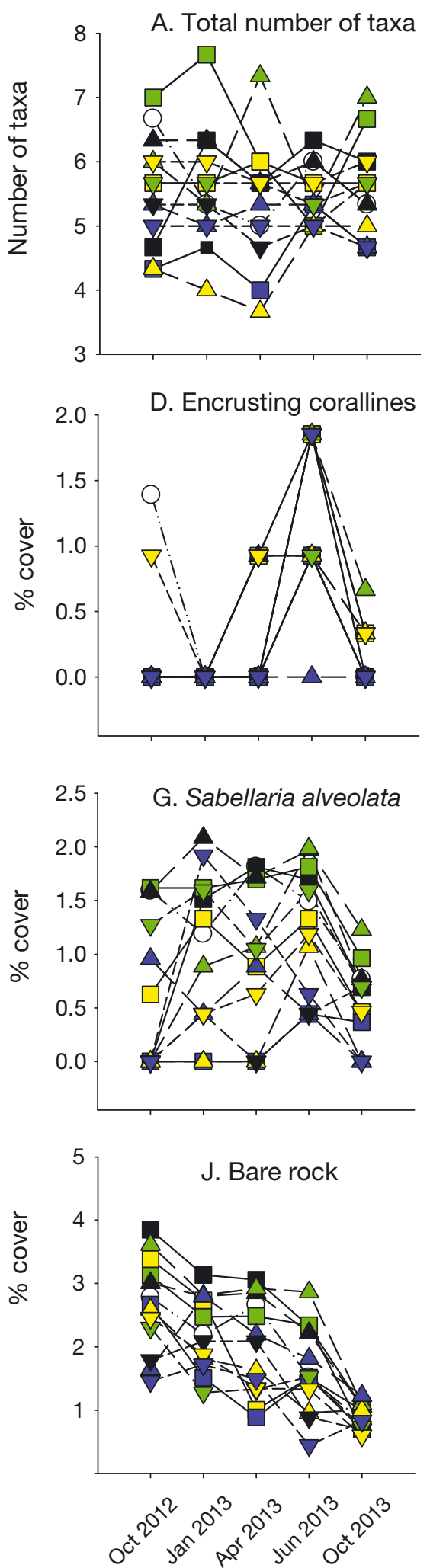
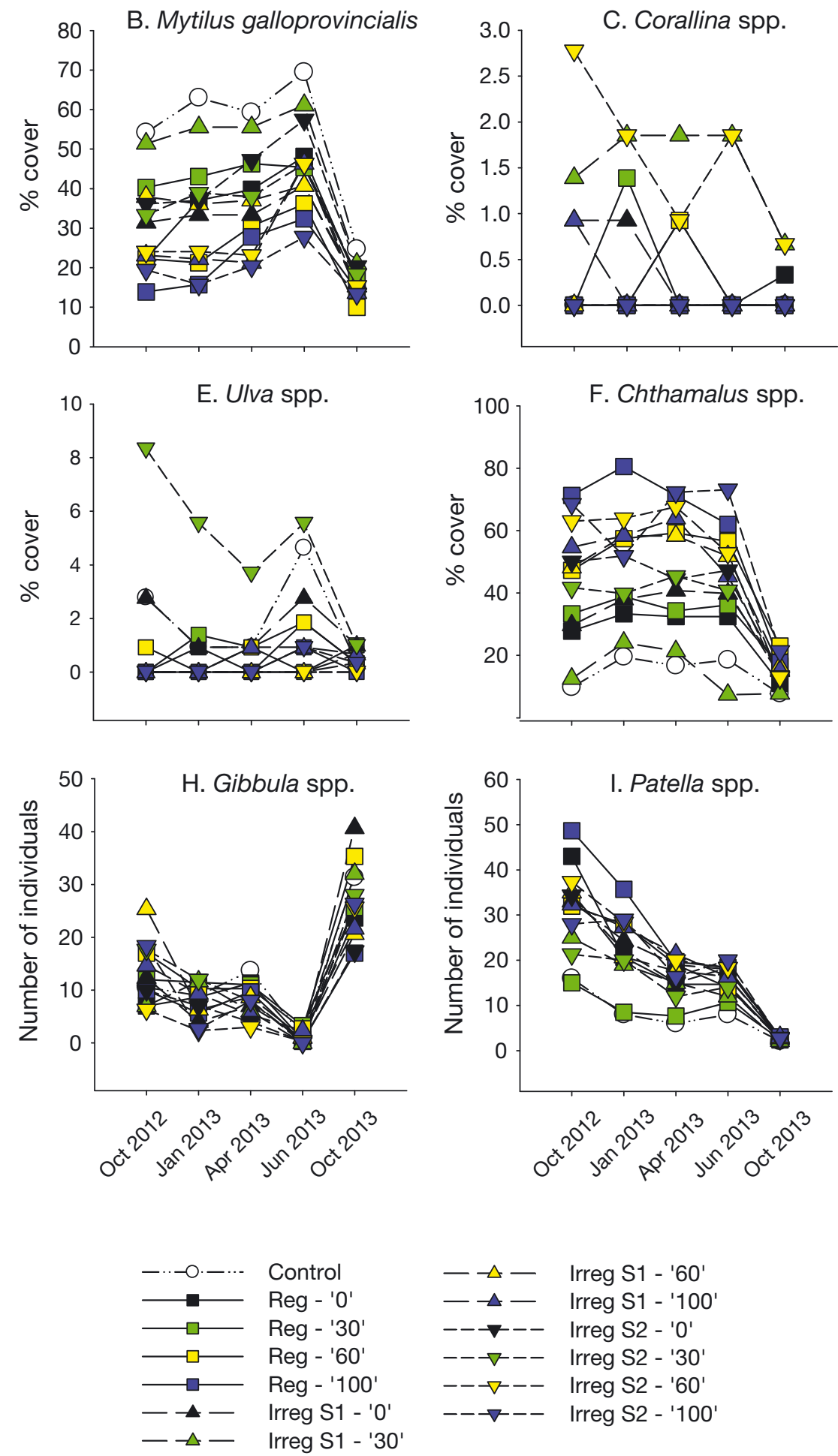

Fig. 4. (A) Mean total number of taxa and (B-J) mean abundance of individual taxa at each sampling period in Aguda. Data averaged over 3 replicate plots assigned to the unmanipulated control and to each combination of past experimental treatments (regular disturbance or irregular disturbance sequence $[S] 1$ or 2 , with ' 0 ', ' $30^{\prime}$ ' ' 60 ' or ' 100 ' \% mussels removed; see

Fig. 1). Standard error bars removed for clarity 

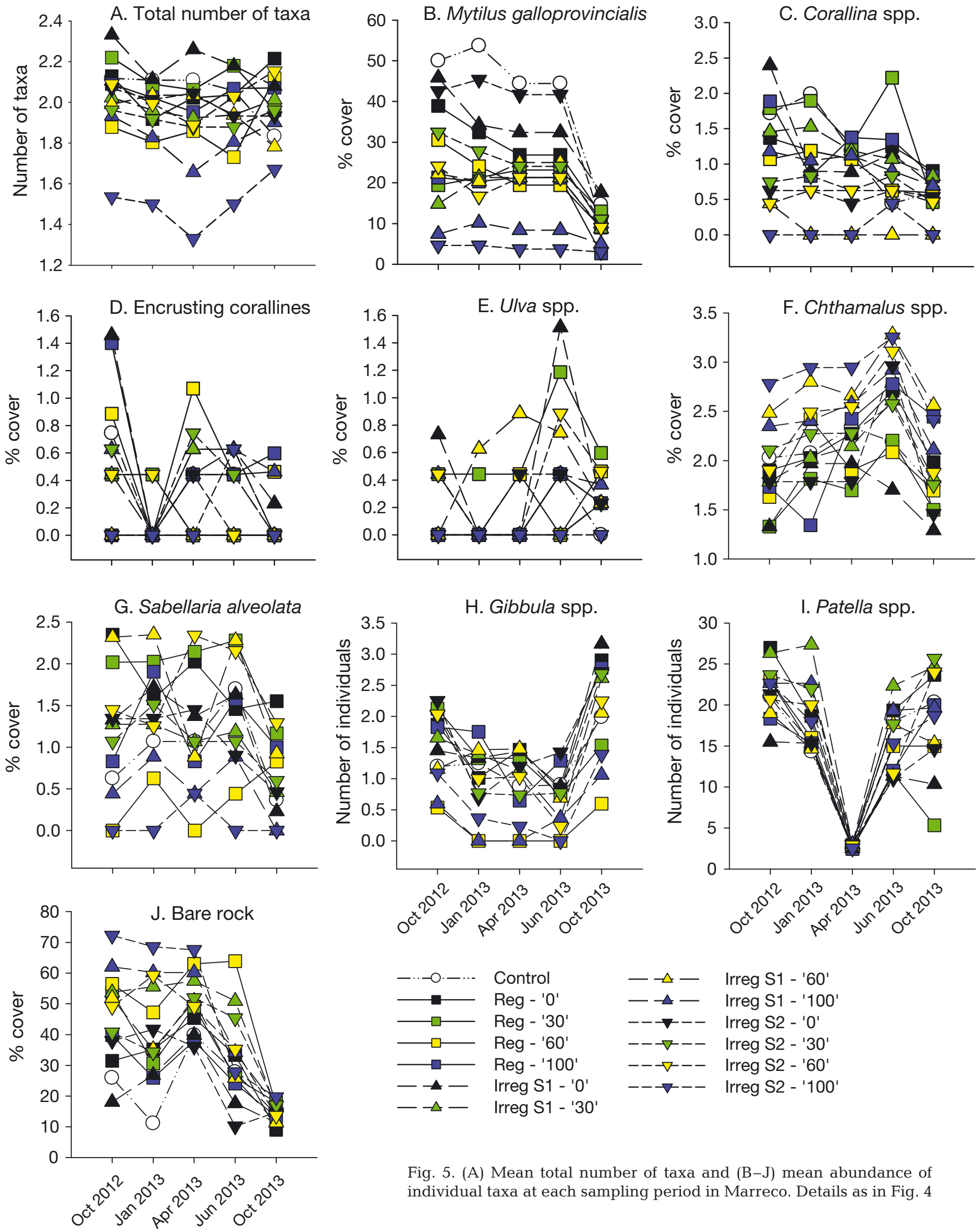

Fig. 5. (A) Mean total number of taxa and (B-J) mean abundance of individual taxa at each sampling period in Marreco. Details as in Fig. 4 
Table 4. Summary of significant results from the ANOVA on the temporal variance of the total number of taxa and the abundance of individual taxa in Aguda (A) and Marreco (M). ${ }^{*} \mathrm{p}<0.05,{ }^{* *} \mathrm{p}<0.01,{ }^{* * *} \mathrm{p}<0.001$

\begin{tabular}{|c|c|c|c|c|c|}
\hline Variable & Site & Source of variation & MS & $F$ & Transf. \\
\hline \multirow[t]{2}{*}{ Total number of taxa } & $\mathrm{A}$ & Control vs. treatments & 3.80 & $6.3^{* *}$ & None $^{a}$ \\
\hline & M & Regular vs. Irregular & 0.37 & $120.2^{*}$ & $\ln (x+1)$ \\
\hline Ulva spp. & M & Between sequences & 1.37 & $4.4^{*}$ & $\ln (x+1)$ \\
\hline \multirow[t]{2}{*}{ Mytilus galloprovincialis } & A & Control vs. treatments & 133245.53 & $6.6^{*}$ & None \\
\hline & M & Control vs. treatments & 79288.83 & $7.3^{*}$ & None \\
\hline \multirow[t]{3}{*}{ Chthamalus spp. } & $\mathrm{A}$ & Control vs. treatments & 120966.50 & $4.5^{*}$ & None \\
\hline & & Between sequences & 150552.86 & $5.5^{*}$ & \\
\hline & & Harvesting intensity (I) & 294040.71 & $10.8^{* * *}$ & \\
\hline \multirow[t]{2}{*}{ Sabellaria alveolata } & A & Regular vs. Irregular & 3.23 & $38.8^{*}$ & $\ln (x+1)$ \\
\hline & M & I $\times$ Regular vs. Irregular & 5.72 & $63.1^{* *}$ & $\ln (x+1)$ \\
\hline Gibbula spp. & M & I $\times$ Regular vs. Irregular & 6.92 & $17.3^{*}$ & $\ln (x+1)$ \\
\hline Patella spp. & $\mathrm{A}$ & Regular vs. Irregular & 12500.97 & $1479.6^{*}$ & None \\
\hline
\end{tabular}

cally, fluctuations were larger in treated than in control plots, in plots subjected to sequence 2 than in those subjected to sequence 1 of disturbance, and in completely harvested compared to the less intensely harvested ('60' treatment), further less harvested ('30' treatment) or mussel-intact plots (Fig. 4F; SNK test).

The mean cover of Sabellaria alveolata did not show any significant differences in both Aguda and Marreco at each of the 3 analyzed periods of recovery (Table 3, Figs. 4G \& 5G). Nevertheless, the temporal variance in the abundance of this species was affected by the temporal variability of past disturbance in Aguda, with larger fluctuations being observed in previously irregularly than in regularly disturbed plots (Table 4, Fig. 4G), and by the interactive effect of the temporal variability and the harvesting intensity in Marreco (Table 4). The pattern of recovery of $S$. alveolata in Marreco was more variable over time in plots that had been subjected to regular events of mechanical disturbance when disturbance had been combined with the total removal of mussels than when mussels had been left untouched, or slightly ('30' treatment) harvested, or when they had been more intensely ('60' treatment) harvested. In contrast, in plots subjected to irregular disturbance, the largest fluctuations in $S$. alveolata abundance were observed in combination with the ' 60 ' treatment, with progressively lower variance values in combination with the unmanipulated, the ' 30 ' and the '100' treatments (Fig. 5G; SNK test).

Patterns of recovery of gastropods of the genus Gibbula in Aguda did not show significant effects of past disturbances both in terms of mean abundances (in October 2012, April 2013 and October 2013) and of temporal variance (Tables 3A \& 4, Fig. 4H). In contrast, a significant Intensity $\times$ Regular vs. Irregular interaction was detected in Marreco in October 2012 (Table 3B), with the mean abundance of Gibbula spp. decreasing progressively from control plots to treatments '30', '100' and '60' when combined with regular events of disturbance, and from treatment ' 60 ' to the control to treatments '30' and '100' when combined with irregular events of disturbance (Fig. $5 \mathrm{H}_{\text {; }}$ SNK test). Such differences disappeared in April 2013. Temporal variations in abundance over the recovery period were affected by combinations of harvesting intensity and the temporal variability of disturbance (Table 4). In plots that had been regularly disturbed, temporal fluctuations in Gibbula spp. abundance progressively decreased from treatment ' 100 ', to the control, to treatments ' 30 ' and ' 60 ', while they progressively decreased from treatment ' 60 ', to the control, to treatments ' 30 ' and '100' in plots that had been irregularly disturbed (Fig. 5H; SNK test).

The mean abundance of limpets (Patella spp.) in Aguda was higher in treated than in control plots in October 2013 and April 2013 (Table 3A, Fig. 4I). Moreover, this variable also varied during the first sampling period in plots allocated to combinations of experimental levels of harvesting and temporal patterns of disturbance (Table 3A). Specifically, where the pattern of disturbance was regular, the most intensely harvested treatments ('100' and '60') had more limpets than the unmanipulated control, or the ' 30 ' treatment. Conversely, where events of disturbance were irregularly distributed, limpets were less abundant in the '30' treatment than in any other level of harvesting, including the unmanipulated control (Fig. 4I; SNK test). In Marreco, no significant 
differences were observed in the abundance of limpets in October 2012, while effects of past treatments were detected later (Table 3B). In April 2013, independent of the intensity of harvesting, plots subjected to the irregular level of disturbance hosted more limpets than those subjected to the regular level (Fig. 5I). In October 2013, the patterns of mean abundance of Patella spp. were very variable depending on the combination of harvesting intensity and temporal pattern of disturbance. Regularly distributed disturbance events were associated with a relatively higher abundance of limpets in both the unmanipulated plots and in those where mussels had been completely removed than in plots allocated to the ' 60 ' treatment, with a further reduction in '30' plots. When irregularly distributed events of disturbance had been applied, their sequence was also important 15 mo after the end of the disturbance experiment, as sequence 1 was associated with a higher number of limpet individuals in the control and in the '30' and '100' treatments compared to the '60' treatment, while sequence 2 was associated with a higher abundance in treatments ' 30 ' and '60' compared to the other 2 levels (Fig. 5I; SNK test). In terms of temporal variance, patterns of limpet abundance in Aguda were characterized by larger fluctuations in plots that were previously regularly disturbed than in those subjected to irregular disturbance (Table 4, Fig. 4I).

Finally, past disturbance affected the availability of bare rock during the recovery process (Table 3 ). In Aguda, similar results were obtained in October 2012 and April 2013, with more bare rock becoming available in plots that were previously irregularly disturbed using sequence 1 than in those disturbed using sequence 2, and independently of the temporal variability of disturbance in the control or the relatively less harvested ('30') plots than in intensely harvested ('60' and '100') plots (Table 3A, Fig. 4J; SNK test). No significant effects were evident in October 2013. In Marreco, past combinations of harvesting intensities and temporal variability of disturbance were associated with significant differences in the amount of free substratum only in April 2013 (Table 3B). In regularly disturbed plots, the availability of bare rock was highest under the ' 60 ' treatment, decreased in both the ' 30 ' treatment and the control, and was further reduced where mussels had been completely removed. In contrast, in irregularly disturbed plots, the greatest amount of bare rock was observed under the complete harvesting treatment, with the amount of bare rock decreasing in both intermediate levels of harvesting and further dimin- ishing where the mussel bed had been left untouched (Fig. 5J; SNK test). However, no significant differences in the temporal variance of the availability of bare rock were found in both study sites (Table 4, Figs. 4J \& 5J).

\section{DISCUSSION}

This study followed a previous experiment that demonstrated the buffering ability of an intact mussel bed against the effects of physical disturbance (see Oliveira et al. 2014). The present work was aimed at evaluating the influence of each combination of past disturbances on the recovery process of assemblages, under the main hypotheses that assemblages associated with an intact mussel bed subjected to regularly distributed events of mechanical disturbance would be more similar and would take less time to converge towards unmanipulated assemblages than those associated with a partly damaged or completely removed mussel bed subjected to irregular disturbance.

The present findings suggest relatively short-term 'legacy' effects of experienced disturbances, although we were unable to fully exclude further subtle consequences of past experimental treatments which might become visible over temporal scales larger than that examined here. In fact, 15 mo after the end of all manipulations, no differences due to any combination of treatments were yet found for multivariate and most univariate response variables, suggesting a strong overall ability of the examined organisms to converge towards the unmanipulated control over such temporal scale. Effects of both the intensity of mussel harvesting and the variability of mechanical disturbance were evident at the earlier sampling dates, although patterns were not consistent between the 2 study sites. While whole assemblages differed between control and, on average, treated plots at both sites 3 mo after the end of the manipulative experiment, the interaction of harvesting intensity and sequence of irregularly distributed events of mechanical disturbance was significant only in Aguda, particularly when a small removal of the mussel bed was combined with sequence 1 of disturbance and when full removal was combined with sequence 2. Six months later, simultaneous, but separate, effects of harvesting intensity and temporal variability of disturbance on the structure of assemblages were still evident in Aguda, while assemblages in Marreco were affected only by a main effect of the temporal variability of disturbance. The 
present findings do not clearly support the proposed hypothesis, although a more intense removal of mussels and a larger temporal variability of disturbance seemed to be independently important in preventing a quick recovery in Aguda and Marreco, respectively.

It could be hypothesized that multivariate patterns might be driven by the responses of manipulated habitat-forming mussels, but effects on recovering Mytilus galloprovincialis only partly matched those on whole assemblages. In general, the abundance of mussels in Aguda was inversely related to the intensity of past harvesting, with more prolonged significant effects due to more intense past removal. This is consistent with the documented ability of mussels to occupy space on rocky shores and to relatively quickly re-colonize disturbed patches, particularly in the absence of effective consumers (e.g. Bertness et al. 2004). The drastic reduction in the cover of mussels observed in control plots in October 2013, however, was responsible for a clear reduction in differences in the cover of mussels relative to all treated plots at both study sites. More complicated to interpret is the significant effect of the sequence of mechanical disturbance events documented in Marreco in October 2013. This effect is likely due to the different timing of events of disturbance established according to each sequence and differences in interacting with some relevant life cycle stages of M. galloprovincialis. The recruitment and settlement of this species at Portuguese locations are known to occur throughout the year, but with peaks from May to September (Fragoso \& Icely 2009). Over the duration of the manipulative experiment, just 2 events (one in July 2011 and another in May 2012) of disturbance were established according to sequence 1 , while 2 sets of consecutive events ( 3 between July and September 2011, and 2 between May and June 2012) were established according to sequence 2 . Such difference might have differentially affected phases of the life cycle of mussels that could be relevant to their ability to recover after disturbance. For instance, it has been shown that extremely stressful conditions occurring at the time of recruitment of several sessile species, including M. galloprovincialis, can drastically affect their patterns of distribution and abundance (Wethey et al. 2011). Analogously, clustered events of disturbance associated with sequence 2 might have hampered the attachment of mussel larvae to rocks, resulting in lower abundances of mussels (compared to sequence 1) recorded much later. Of course, the establishment of exactly the same treatments at both sites should have implied analo- gous findings also in Aguda, but this was not the case. This could be explained by differences between the 2 study sites in other physical and biological processes that were impossible to control despite the 2 sites being comparable in a number of identified factors. For example, complex and almost unpredictable variations in the availability of larvae of sessile organisms can be responsible for the variability in their patterns of colonization over a spatial scale comparable to that between Aguda and Marreco (e.g. Raimondi 1990).

Site-specific processes might have also been responsible for the inconsistent responses documented for the total number of taxa (a proxy for species richness). When the temporal variability of mechanical disturbance was the key factor, such as in Aguda 3 mo after the end of the disturbance experiment, the richness of taxa was higher in previously irregularly disturbed plots compared to regularly disturbed plots. This would be consistent with the supposed relatively greater ability of past irregular disturbance events to generate a mosaic of resources usable by a larger set of taxa (Dayton 1971, Connell 1978, Lubchenco \& Menge 1978, Paine \& Levin 1981, Sousa 1984). Absolute differences in the number of taxa, however, were always very small, suggesting that caution should be exercised in attributing crucial ecological importance to this mechanism. Moreover, site-specific inconsistencies suggest that any possible relationship between past disturbances and subsequent patterns of richness of recovering assemblages might not be as relevant as the effects of other processes. For example, in Aguda, the articulated coralline algae of the genus Corallina showed initial patterns of recovery that were affected by the temporal variability of past disturbance, this taxon being present only in regularly disturbed and absent in irregularly disturbed plots. In principle, it could be expected that events of disturbance clustered over reduced periods of time could be particularly stressful for most organisms whose abundance might be reduced to lower values than by regular disturbance, these organisms eventually needing more time to recover (Benedetti-Cecchi 2003, Bertocci et al. 2005). However, previous findings suggested that Corallina spp. may benefit from relatively stressful conditions due to its mechanical resistance and its concomitant release from competition with more sensitive species (Bulleri \& Airoldi 2005, Oliveira et al. 2014). The present findings clearly disagree with these previous findings, which might suggest that the direct effect of disturbance would not be as relevant for their patterns of recovery as the indirect influence of other 
processes. These other processes might also include competitive and/or grazing relationships with other sessile organisms that are also affected by disturbance in a contrasting way. Intense grazing by limpets, in particular, can almost completely eliminate erect seaweeds, including articulated corallines, from patches of rocky substratum (e.g. BenedettiCecchi et al. 1996). In October 2012, limpets of the genus Patella were relatively more abundant (in contrast to Corallina spp.) in Aguda in plots where mussels had been intensely removed, and where regularly distributed events of mechanical disturbance had been applied, suggesting a possible grazing effect on these algae.

The interaction with different types of disturbance and the ability to occupy space in competition with co-occurring organisms was likely responsible for the patterns of recovery of encrusting coralline algae, although patterns were again inconsistent between sites. While control plots in Aguda were characterized by higher cover values of this taxon compared to treated plots only 3 mo after the end of the experiment and differences were no longer evident at the next analyzed periods of recovery, later differences were detected in Marreco depending on the interaction between the intensity of mussel harvesting and the variability of storm-like disturbances. Specifically, an intact mussel bed could buffer the effects of physical disturbances occurring through single events that are regularly distributed in time, while more aggregated events could create free patches suitable for the colonization and increase in abundance of encrusting corallines (see also Oliveira et al. 2014). This is consistent with the known resistance of these algae to mechanical disturbance and with their subsequent colonization of disturbed patches (e.g. Bulleri 2006). When mussels were intensely removed, however, the combination with clustered disturbance events (in principle the condition potentially able to create larger free patches) was surprisingly associated with the virtual absence of encrusting corallines, which, instead, increased in abundance in plots that were previously disturbed according to the regular pattern. These results are unlikely due to a negative effect of the most stressful combination of past experimental manipulations that exceeded the resistance ability of this algal group (see also Oliveira et al. 2014); however, possible explanations for the present outcome should be found in indirect effects of past treatments. Such mechanisms could be speculated based on the present results, but are beyond the goals of this discussion.
It is interesting to notice, however, that another taxon that is dependent on the availability of free space, i.e. the barnacle Chthamalus spp. (e.g. Bertness et al. 2004), was generally positively affected by the intensity of mussel harvesting. Especially in Aguda, both the mean abundance and the temporal variance of barnacle abundance tended to be higher in intensely harvested (' 60 ' and '100' treatments) plots. Nevertheless, the patterns of availability of bare rock during the examined recovery period of assemblages could not support a simple interpretation of the present results, as a larger amount of free space tended to be available in plots that had been subjected to the lower levels of harvesting. This can be explained by the ability of other taxa to colonize large patches left by removed mussels and to exclude barnacles from them. In contrast, smaller patches could have represented a refuge for recovering barnacles, once their larvae were present at the suitable time (Keough 1984). In fact, the sequence of disturbance was also relevant for Chthamalus spp. Populations of C. stellatus from nearby locations were shown to have their peaks of recruitment during summer months (i.e. from June to late August; O'Riordan et al. 2004), when different numbers of experimental events of disturbance had been performed for each sequence (a single event in 2011 for sequence 1, but 2 consecutive events in both 2011 and 2012 for sequence 2). This might have affected the subsequent patterns of recovery of barnacles in disturbed plots.

A potential competitor of barnacles for substratum could be represented by the honeycomb worm $\mathrm{Sa}$ bellaria alveolata which, particularly in Marreco, appeared to benefit from the protection provided by an intact mussel bed (and from its ability to live within and below mussel individuals) when events of disturbance had been clustered; when disturbance events had been regularly established, the worm increased in abundance after the full removal of mussels. In the absence of major disturbances, this reefbuilding polychaete is described as a dominant habitat-former (e.g. Wethey et al. 2011).

As could be expected, the top shells Gibbula spp. showed little effects of past disturbances, likely due to their mobility allowing them to quickly re-invade disturbed patches. In the first stages of recovery in Marreco, however, the integrity of the mussel bed was an important factor for these gastropods as their abundance still appeared to decrease with increase in harvesting intensity, reaching the lowest values in the most extremely disturbed plots (i.e. those where mussels had been completely reduced and those 
where irregular storm-like disturbance events had been performed). This was also the combination of past treatments that was associated with the relatively lowest value of the temporal variance of the abundance of Gibbula spp. over the examined period, in agreement with predictions from the scaling relationship between the mean and the variance, by which large fluctuations around consistently low values would not be intrinsically possible (Taylor 1961). For these animals, it is logical to hypothesize that an intact mussel bed could provide protection from physical disturbance and/or predators, while increasing mussel removal would expose them to increasing stress, leading to a decrease in abundances (e.g. Underwood 1998).

Independent of the specific mechanisms underlying the present outcomes, this study demonstrated that assemblages that mostly include organisms known to withstand 'extreme' combinations of types, mean intensity and temporal variability of disturbance can quickly converge toward unmanipulated ones. Although high resilience is a key property of intertidal organisms (Steneck 1986, Benedetti-Cecchi 2000, Bertocci et al. 2005), the present findings raise some warning considerations.

First, within the same level of temporal variance, the sequence of disturbances was shown to be responsible for modifications both in the mean abundance and the temporal variance of recovering organisms, likely due to its interference with biological traits such as reproduction, recruitment and growth seasons. This suggests the need to design manipulative experiments that take this point into account when examining hypotheses in ecological contexts similar to those of the present study (Vaselli et al. 2008, Oliveira et al. 2014, Tamburello et al. 2014). This also raises several questions regarding the timing of the implementation of planned disturbances in coastal areas, such as beach nourishment interventions (e.g. Schlacher \& Thompson 2012) and other construction works (e.g. Airoldi \& Beck 2007). Wherever possible, these operations should be done with reference to the timing of life cycles of the main exposed organisms in order to guarantee their better and faster recovery.

Second, ecological theories consider disturbance, with the consequent elimination of dominant organisms, as an opportunity for other, less competitive, species to colonize and grow in otherwise unsuitable conditions, which could eventually lead to an increase in the diversity (particularly species richness) of the system (Connell 1978, Huston 1994, Connell et al. 1997). In this study, the set and total number of taxa found in experimental plots before and during manipulations (Oliveira et al. 2014) and during the recovery period remained almost unaltered. This suggests that the main effects of disturbance can be in terms of changes in the relative abundance of the same taxa, rather than in changes in the identity or the overall richness of taxa (O'Connor \& Crowe 2005, Cardinale et al. 2006, Stachowicz et al. 2007, Maggi et al. 2009, Bertocci et al. 2010).

In conclusion, this study contributes answers to questions about the growing influence of compounded anthropogenic perturbations on coastal areas, particularly on how different life traits can allow exposed organisms to cope with multiple disturbances through modifications of their patterns of recovery over a definite time frame.

Acknowledgements. This study is part of a $\mathrm{PhD}$ dissertation by J.P.O. at the University of Porto, ICBAS, funded by the Littoral Station of Aguda. I.B. was supported by Fundação para a Ciência e a Tecnologia (FCT) within the Programa Ciência 2008-Fundo Social Europeu. Additional funding was provided by the European Regional Development Fund (ERDF) through the programme POFC-COMPETE within the Quadro de Referência Estratégico Nacional (QREN) and the FCT through national funds (PEst-C/MAR/LA0015/ 2011). R. Dominguez, A. Plicanti and F. De Cristofaro assisted with field work.

\section{LITERATURE CITED}

Addessi L (1994) Human disturbance and long-term changes on a rocky intertidal community. Ecol Appl 4: 786-797

Airoldi L (2000) Responses of algae with different life histories to temporal and spatial variability of disturbance in subtidal reefs. Mar Ecol Prog Ser 195:81-92

Airoldi L, Beck MW (2007) Loss, status and trends for coastal habitats of Europe. Oceanogr Mar Biol Annu Rev 45: 345-405

- Alvarado JL, Pinto R, Marquet P, Pacheco C, Guiñez R, Castilla JC (2001) Patch recolonization by the tunicate Pyura praeputialis in the rocky intertidal of the Bay of Antofagasta, Chile: evidence for self-facilitation mechanisms. Mar Ecol Prog Ser 224:93-101

Anderson MJ (2001) A new method for non-parametric multivariate analysis of variance. Austral Ecol 26:32-46

Anderson MJ, Robinson J (2003) Generalized discriminant analysis based on distances. Aust NZ J Stat 45:301-318

Anderson MJ, Gorley RN, Clarke KR (2008). PERMANOVA+ for PRIMER: guide to software and statistical methods. PRIMER-E, Plymouth

Bell EC (1993) Photosynthetic response to temperature and desiccation of the intertidal alga Mastocarpus papillatus. Mar Biol 117:337-346

Benedetti-Cecchi L (2000) Priority effects, taxonomic resolution, and the prediction of variable patterns of colonisation of algae in littoral rock pools. Oecologia 123:265-274 Benedetti-Cecchi L (2003) The importance of the variance 
around the mean effect size of ecological processes. Ecology 84:2335-2346

> Benedetti-Cecchi L, Airoldi L, Abbiati M, Cinelli F (1996) Estimating the abundance of benthic invertebrates: a comparison of procedures and variability between observers. Mar Ecol Prog Ser 138:93-101

> Bertness MD, Trussell GC, Ewanchuk PJ, Silliman BR, Mullan Crain C (2004) Consumer-controlled community states on Gulf of Maine rocky shores. Ecology 85: 1321-1331

Bertocci I, Maggi E, Vaselli S, Benedetti-Cecchi L (2005) Contrasting effects of mean intensity and temporal variation of disturbance on assemblages of rocky shores. Ecology 86:2061-2067

> Bertocci I, Arenas F, Matias M, Vaselli S and others (2010) Canopy-forming species mediate the effects of disturbance on macroalgal assemblages on Portuguese rocky shores. Mar Ecol Prog Ser 414:107-116

> Bevilacqua S, Terlizzi A, Fraschetti S, Russo GF, Boero F (2006) Mitigating human disturbance: Can protection influence trajectories of recovery in benthic assemblages? J Anim Ecol 75:908-920

> Blanchette CA (1996) Seasonal patterns of disturbance influence recruitment of the sea palm, Postelsia palmaeformis. J Exp Mar Biol Ecol 197:1-14

Breitburg DL (1985) Development of a subtidal epibenthic community: factors affecting species composition and the mechanisms of succession. Oecologia 65:173-184

Bulleri F (2006) Duration of overgrowth affects survival of encrusting coralline algae. Mar Ecol Prog Ser 321:79-85

Bulleri F, Airoldi L (2005) Artificial marine structures facilitate the spread of a non-indigenous marine alga, Codium fragile ssp. tomentosoides, in the north Adriatic Sea. J Appl Ecol 42:1063-1072

> Cardinale BJ, Srivastava DS, Duffy JE, Wright JP, Downing AL, Sankaran M, Jouseau C (2006) Effects of biodiversity on the functioning of trophic groups and ecosystems. Nature 443:989-992

Carr MH, Neigel JL, Estes JA, Andelman S, Warner RR, Largier JL (2003) Comparing marine and terrestrial ecosystems: implications for the design of coastal marine reserves. Ecol Appl 13:90-107

> Castilla JC (1999) Coastal marine communities: trends and perspectives from human exclusion experiments. Trends Ecol Evol 14:280-283

> Cervin G, Åberg P, Jenkins SR (2005) Small-scale disturbance in a stable canopy dominated community: implications for macroalgal recruitment and growth. Mar Ecol Prog Ser 305:31-40

> Connell JH (1978) Diversity in tropical rain forests and coral reefs. Science 199:1302-1310

Connell JH, Keough MJ (1985) Patch dynamics of subtidal marine animals on hard substrata. In: Pickett STA, White PS (eds) The ecology of natural disturbance and patch dynamics. Academic Press, New York, NY, p 121-151

> Connell JH, Hughes TP, Wallace CC (1997) A 30 year study of coral abundance, recruitment, and disturbance at several scales in space and time. Ecol Monogr 67:461-488

Crowe TP, Thompson RC, Bray S, Hawkins SJ (2000) Impacts of anthropogenic stress on rocky intertidal communities. J Aquat Ecosyst Stress Recovery 7:273-297

Dayton PK (1971) Competition, disturbance and community organization: the provision and subsequent utilization of space in a rocky intertidal community. Ecol Monogr 41: 351-389
Easterling DR, Meehl GA, Parmesan C, Changnon SA, Karl TR, Mearns LO (2000) Climate extremes: observations, modeling, and impacts. Science 289:2068-2074

Fragoso B, Icely JD (2009) Upwelling events and recruitment patterns of the major fouling species on coastal aquaculture (Sagres, Portugal). J Coast Res SI 56:419-423

> Gray JS (1997) Marine biodiversity: patterns, threats and conservation needs. Biodivers Conserv 6:153-175

> Griffiths CL, Branch GM (1997) The exploitation of coastal invertebrates and seaweeds in South Africa: historical trends, ecological impacts and implications for management. Trans R Soc S Afr 52:121-148

Grime JP, Brown VK, Thompson K, Masters GJ and others (2000) The response of two contrasting limestone grasslands to simulated climate change. Science 289:762-765

Halpern BS, Walbridge S, Selkoe KA, Kappel CV and others (2008) A global map of human impact on marine ecosystems. Science 319:948-952

Hoffmann AJ, Ugarte R (1985) The arrival of propagules of marine macroalgae in the intertidal zone. J Exp Mar Biol Ecol 92:83-95

Huston M (1994) Biological diversity. Cambridge University Press, Cambridge

Inchausti P, Halley J (2003) On the relation between temporal variability and persistence time in animal populations. J Anim Ecol 72:899-908

Johnson KH, Vogt KA, Clark HJ, Schmitz OJ, Vogt DJ (1996) Biodiversity and the productivity and stability of ecosystems. Trends Ecol Evol 11:372-377

- Keough MJ (1984) Effects of patch size on the abundance of sessile marine invertebrates. Ecology 65:423-437

Keough MJ, Quinn GP, King A (1993) Correlations between human collecting and intertidal mollusc populations on rocky shores. Conserv Biol 7:378-390

Lubchenco J, Menge BA (1978) Community development and persistence in a low rocky intertidal zone. Ecol Monogr 48:67-94

> Lundberg P, Ranta E, Ripa J, Kaitala V (2000) Population variability in space and time. Trends Ecol Evol 15: 460-464

> Maggi E, Bertocci I, Vaselli S, Benedetti-Cecchi L (2009) Effects of changes in number, identity and abundance of habitat-forming species on assemblages of rocky shores. Mar Ecol Prog Ser 381:39-49

> Maggi E, Bertocci I, Vaselli S, Benedetti-Cecchi L (2011) Connell and Slatyer's models of succession in the biodiversity era. Ecology 92:1399-1406

> McArdle BH, Anderson MJ (2001) Fitting multivariate models to community data: a comment on distance-based redundancy analysis. Ecology 82:290-297

Meehl GA, Stocker TF, Collins WD, Friedlingstein P and others (2007) Global climate projections. In: Solomon S, Qin D, Manning M, Chen Z and others (eds) Climate change 2007: the physical science basis. Contribution of Working Group I to the Fourth Assessment Report of the Intergovernmental Panel on Climate Change. Cambridge University Press, Cambridge, p 747-846

> Menge BA, Sutherland JP (1987) Community regulation: variation in disturbance, competition, and predation in relation to environmental stress and recruitment. Am Nat 130:730-757

Micheli F, Cottingham KL, Bascompte J, Bjornstad ON and others (1999) The dual nature of community variability. Oikos 85:161-169

Muller RA, Stone GW (2001) A climatology of tropical storm 
and hurricane strikes to enhance vulnerability prediction for the southeast U.S. coast. J Coast Res 17:949-956

> O'Connor KC, Anderson TW (2010) Consequences of habitat disturbance and recovery to recruitment and the abundance of kelp forest fishes. J Exp Mar Biol Ecol 386: $1-10$

O'Connor NE, Crowe TP (2005) Biodiversity and ecosystem functioning: distinguishing between effects of the number of species and their identities. Ecology 86:1783-1796

O'Riordan RM, Arenas F, Arrontes J, Castro JJ and others (2004) Spatial variation in the recruitment of the intertidal barnacles Chthamalus montagui Southward and Chthamalus stellatus (Poli) (Crustacea: Cirripedia) over an European scale. J Exp Mar Biol Ecol 304:243-264

> Oliveira JP, Bertocci I, Weber GM, Sousa-Pinto I (2011) Type and timing of disturbance modify trajectories of recovery of rockpool assemblages at Aguda (NW Portugal). J Exp Mar Biol Ecol 399:135-141

Oliveira JP, Sousa-Pinto I, Weber GM, Bertocci I (2014) Interplay of experimental harvesting and climate-related disturbance on benthic assemblages of rocky seashores. Mar Ecol Prog Ser 495:131-142

Paine RT, Levin SA (1981) Intertidal landscapes: disturbance and the dynamics of pattern. Ecol Monogr 51:145-178

> Paine RT, Tegner MJ, Johnson EA (1998) Compounded perturbations yield ecological surprises. Ecosystems 1: 535-545

Raimondi PT (1990) Patterns, mechanisms, consequences of variability in settlement and recruitment of an intertidal barnacle. Ecol Monogr 60:283-309

Reed DC (1990) The effects of variable settlement and early competition on patterns of kelp recruitment. Ecology 71: 776-787

Sala OE, Stuart Chapin FS III, Armesto JJ, Berlow E and others (2000) Global biodiversity scenarios for the year 2100. Science 287:1770-1774

Schlacher TA, Thompson L (2012) Beach recreation impacts benthic invertebrates on ocean-exposed sandy shores. Biol Conserv 147:123-132

Searle SR, Casella G, McCulloch C (1992) Variance components. Wiley, New York, NY

Siegfried WR, Hockey PAR, Branch GM (1994) The exploitation of intertidal and subtidal biotic resources of rocky shores in Chile and South Africa-an overview. In: Siegfried RS (ed) Rocky shores: exploitation in Chile and South Africa. Springer-Verlag, Berlin, p 1-13

Sousa WP (1984) The role of disturbance in natural communities. Annu Rev Ecol Evol Syst 15:353-391

Speidel M, Harley CDG, Wonham MJ (2001) Recovery of the brown alga Fucus gardneri following a range of removal intensities. Aquat Bot 71:273-280

Stachowicz JJ, Bruno JF, Duffy JE (2007) Understanding the effects of marine biodiversity on communities and ecosystems. Annu Rev Ecol Evol Syst 38:739-766

Steneck RS (1986) The ecology of coralline algal crusts: convergent patterns and adaptative strategies. Annu Rev Ecol Syst 17:273-303

Tamburello L, Bulleri F, Balata D, Benedetti-Cecchi L (2014) The role of overgrazing and anthropogenic disturbance in shaping spatial patterns of distribution of an invasive seaweed. J Appl Ecol 51:406-414

- Taylor LR (1961) Aggregation, variance, and the mean. Nature 189:732-735

Terlizzi A, Anderson MJ, Fraschetti S, Benedetti-Cecchi L (2007) Scales of spatial variation in Mediterranean subtidal sessile assemblages at different depths. Mar Ecol Prog Ser 332:25-39

Underwood AJ (1989) The analysis of stress in natural populations. Biol J Linn Soc 37:51-78

- Underwood AJ (1993) Exploitation of species on the rocky coast of New South Wales (Australia) and options for its management. Ocean Coast Manag 20:41-62

> Underwood AJ (1996) Detection, interpretation, prediction and management of environmental disturbances: some roles for experimental marine ecology. J Exp Mar Biol Ecol 200:1-27

Underwood AJ (1997) Experiments in ecology: their logical design and interpretation using analysis of variance. Cambridge University Press, Cambridge

Underwood AJ (1998) Grazing and disturbance: an experimental analysis of patchiness in recovery from a severe storm by the intertidal alga Hormosira banksii on rocky shores in New South Wales. J Exp Mar Biol Ecol 231: 291-306

> Underwood AJ, Denley EJ, Moran MJ (1983) Experimental analyses of the structure and dynamics of mid-shore rocky intertidal communities in New South Wales. Oecologia 56:202-219

Underwood AJ, Chapman MG, Richards SA (2002) GMAV5 for Windows. An analysis of variance programme. Centre for Research on Ecological Impacts of Coastal Cities, Marine Ecology Laboratories, University of Sydney

> van Tamelen PG (1996) Algal zonation in tidepools: experimental evaluation of the roles of physical disturbance, herbivory and competition. J Exp Mar Biol Ecol 201: 197-231

Vaselli S, Bertocci I, Maggi E, Benedetti-Cecchi L (2008) Effects of mean intensity and temporal variance of sediment scouring events on assemblages of rocky shores. Mar Ecol Prog Ser 364:57-66

> Vitousek PM, Mooney HA, Lubchenco J, Melillo JM (1997) Human domination of Earth's ecosystems. Science 277: 494-499

Watling L, Norse EA (1998) Disturbance of the seabed by mobile fishing gear: a comparison to forest clearcutting. Conserv Biol 12:1180-1197

Wethey DS, Woodin SA, Hilbish TJ, Jones SJ, Lima FP, Brannock PM (2011) Response of intertidal populations to climate: effects of extreme events versus long term change. J Exp Mar Biol Ecol 400:132-144

- Williams SL, Smith JE (2007) A global review of the distribution, taxonomy, and impacts of introduced seaweeds. Annu Rev Ecol Evol Syst 38:327-359

Wong PP, Losada IJ, Gattuso JP, Hinkel J and others (2014) Coastal systems and low-lying areas. In: Field C, Barros VR, Dokken DJ, Mach KJ and others (eds) Climate change 2014: impacts, adaptation and vulnerability. Contribution of Working Group II to the Fifth Assessment Report of the Intergovernmental Panel on Climate Change. Cambridge University Press, Cambridge

Submitted: June 5, 2014; Accepted: November 21, 2014

Proofs received from author(s): March 9, 2015
Editorial responsibility: Antony Underwood,

Sydney, New South Wales, Australia 